\title{
Research Article \\ Bilevel Traffic Evacuation Model and Algorithm Design for Large-Scale Activities
}

\author{
Danwen Bao, Jiayu Gu, and Junhua Jia \\ Collage of Civil Aviation, Nanjing University of Aeronautics and Astronautics, Nanjing 210016, China \\ Correspondence should be addressed to Danwen Bao; baodanwen@nuaa.edu.cn
}

Received 28 August 2016; Revised 14 December 2016; Accepted 11 May 2017; Published 13 June 2017

Academic Editor: Gennaro N. Bifulco

Copyright (C) 2017 Danwen Bao et al. This is an open access article distributed under the Creative Commons Attribution License, which permits unrestricted use, distribution, and reproduction in any medium, provided the original work is properly cited.

\begin{abstract}
This paper establishes a bilevel planning model with one master and multiple slaves to solve traffic evacuation problems. The minimum evacuation network saturation and shortest evacuation time are used as the objective functions for the upper-and lowerlevel models, respectively. The optimizing conditions of this model are also analyzed. An improved particle swarm optimization (PSO) method is proposed by introducing an electromagnetism-like mechanism to solve the bilevel model and enhance its convergence efficiency. A case study is carried out using the Nanjing Olympic Sports Center. The results indicate that, for large-scale activities, the average evacuation time of the classic model is shorter but the road saturation distribution is more uneven. Thus, the overall evacuation efficiency of the network is not high. For induced emergencies, the evacuation time of the bilevel planning model is shortened. When the audience arrival rate is increased from $50 \%$ to $100 \%$, the evacuation time is shortened from $22 \%$ to $35 \%$, indicating that the optimization effect of the bilevel planning model is more effective compared to the classic model. Therefore, the model and algorithm presented in this paper can provide a theoretical basis for the traffic-induced evacuation decision making of large-scale activities.
\end{abstract}

\section{Introduction}

China has had an increased influence in politics, culture, economy, and sports in recent years due to its increased international status. There are a number of international largescale activities of various forms held in China, with recent examples including the Beijing Olympic Games, Shanghai World Expo, and Guangzhou Asian Games. These activities enhance the attraction of cities and bring considerable gains but also result in opportunities and challenges. Largescale activities held frequently in various forms improve the construction of infrastructure but impact and influence city traffic. It is important to develop a reasonable and effective traffic evacuation strategy to cope with large-scale activities that are characterized by strong agglomeration, suddenness, and short-term durations.

Research on the organization and management of largescale activities has increased with the increasing prevalence of international events; in particular, the recent Olympic Games provide sufficient data and experience for such research.
Amodei et al. [1-4] studied the experiences in traffic organization and management from the Atlanta Olympic Games in 1996, the Sydney Olympic Games in 2000, the Salt Lake City Winter Olympics in 2002, and the Athens Olympic Games in 2004. The studies focused on the management of traffic demand, planning of public transport, and planning of park and ride. The Federal Highway Administration (FHWA) [5] issued a research report on the traffic management of large-scale activities. It provided a reference but lacked details for establishing a traffic organization method and relevant theories. Liu et al. [6] studied the traffic planning of the Beijing Olympic Games in 2008 and published a report entitled "Traffic Planning for Olympic Games." Chen et al. $[7,8]$ investigated the planning and organization of traffic for the Shanghai World Expo in 2010 and proposed relevant traffic plans. Ma et al. $[9,10]$ proposed detailed planning for the construction and organization of traffic for the Guangzhou Asian Games in 2010. Traffic planning models were established to make quantitative predictions of venue accessibility. The research focused on the macropolicy of 
traffic organization and principles of traffic management; few references have provided an induced evacuation model of traffic and theoretical foundations. After hurricane Katrina swept across New Orleans in 2005, research on that aspect has gradually become thorough. Many scholars applied the traffic flow distribution to the building of an evacuation model. Liu et al. [11] proposed a method that applied a bilevel planning model to evacuation. Chiu et al. [12] introduced a no-notice mass evacuation model. Liu et al. [13] designed a real-time control evacuation system by introducing adaptive control theory. Yazici et al. [14] introduced stochastic road capacity to propose a more robust evacuation method. Yan et al. [15] established a bilevel planning model to study a one-way passing traffic network for the evacuation of largescale activities and rush hour daily commute. The solution algorithm was also proposed. Doan and Ukkusuri [16] studied the traffic flow blocking phenomenon. As an innovation algorithm, Li et al. [17] proposed an approximate solution method. Robustness, optimization, and randomness were also introduced [18]. In addition, meaningful research results were obtained through simulation, such as the research conducted by Naghawi and Wolshon [19] and Zhao et al. [20]. Pel et al. [21] reviewed traffic evacuation problems by using simulation methods. Use of the theory of traffic flow distribution to solve evacuation problems has become a research topic of increasing interest. With the improvement of computer power, these theories have become closer to the actual demands of traffic management. However, the research has been focused on evacuation problems resulting from disaster scenarios that tend to give priority to the victims' survival and property safety. In view of the general growth of large-scale activities, it is worthwhile to study evacuation from the perspective of how to reduce the impact on the surrounding road network and improve traffic efficiency.

A number of studies have focused on traffic organization and evacuation for large-scale activities. There are three main shortcomings. First, the available research on traffic evacuation focuses on management by using simulation software to assess the traffic evacuation plans. However, these empirical plans are not always the optimized plan, and, thus, it is necessary to use mathematical modeling methods to verify their performance. Second, as the bilevel model has been widely used in traffic network design, the upperlevel model is always established based on the practical case and is generally a two-value and continuous problem. Few studies have focused on the multivalue discrete problem. The computational efficiency of the available algorithms is low when there are a large number of network points and large demand for evacuation. There are problems with being trapped in a local optimal solution and premature convergence; thus, the solution algorithm must be optimized. Third, there are many unknowns during large-scale activities that may cause a series of reactions and emergencies. The available models always focus on traffic evacuation for the activity itself rather than the induced emergencies.

This paper establishes a bilevel planning model with a single master and multiple slaves. The minimum saturation of the evacuation network is used as the objective function in the upper-level planning model, whereas the minimum evacuation time for the large-scale activity and induced emergencies is used as the objective function in the lower-level planning model. Traffic evacuations for large-scale activities and induced emergencies are both studied. An improved particle swarm optimization method is proposed to solve the bilevel planning model and enhance its computing efficiency. A case study is performed using the Nanjing Olympic Sports Center to further verify the accuracy and feasibility of the proposed model and solution algorithm. This study intends to provide a reference for the traffic evacuation of large-scale activities.

\section{Establishment of the Model}

2.1. Construction of the Bilevel Planning Model. For a given topological space structure $G(N, A)$ of road network, $N$ is the set of road nodes and $A$ is the set of directed arcs, that is, the set of roads in the network. The modeling objective is to obtain the minimum saturation of the evacuation network. For a large-scale activity, travelers may choose the shortest evacuation path to achieve the shortest individual evacuation time. If emergencies occur during the activity, emergency plans should be initiated to avoid the occurrence of additional accidents. Emergency plans target the shortest total evacuation time, which is achieved by choosing evacuation paths based on system optimization.

A bilevel planning model is proposed using the minimum saturation of the evacuation network as the objective function for the upper-level planning model and the minimum evacuation time as the objective function for the lower-level planning model. The objective function and constraint conditions of the upper-level model depend on the optimal solution of the lower-level planning model, which is in turn affected by the strategy variables in the upper-level model [22]. Based on the dynamic traffic evacuation characteristics for large-scale activities, the upper-level model mainly focuses on the effect of saturation on the practical operation of traffic, whereas the lower-level model mainly considers the shortest total evacuation time of all vehicles. The objective function of the lower-level model is to determine which evacuation model to use under various traffic conditions to obtain the shortest evacuation time. The upper-level model can be expressed as

$$
\begin{aligned}
& \min Z_{0}=\sum_{a} \int_{0}^{T} \frac{x_{a}(t)}{C_{a}} \\
& =\sum_{a} \int_{0}^{T} \frac{d_{k}^{r s}(t) / L_{a}}{3600\left(V_{a}(t) \cdot l_{a} / T_{e}(t)\right) \cdot \gamma} \\
& =\sum_{a} \int_{0}^{T} \frac{d_{k}^{r s}(t) \cdot T(t)_{e}}{3600 V_{a}(t) \cdot L_{a} \cdot l_{a} \cdot \gamma} \\
& \text { s.t } \frac{d x_{a}(t)}{d t}=u_{a}(t)-v_{a}(t) \quad \forall a, t \\
& \sum_{a} V_{a}(t)=\frac{\sum_{a} R_{a}^{t s}(t)}{\sum_{a} C_{a}^{t s}(t) \cdot \lambda \sum_{a} L_{a}} \\
& R_{a}^{t s}(t)=L_{a} \cdot \sum_{a} T_{e}(t),
\end{aligned}
$$


where $Z_{0}$ represents regional road network saturation; $x_{a}(t)$ represents the number of vehicles on evacuation road $a$ at time $t ; C_{a}$ represents the capacity of evacuation $\operatorname{road} a ; d_{k}^{r s}(t)$ represents the traffic demand at time $t$ on path $k$ between $r$ and $s$ of OD point pairs in units of pcu; $L_{a}$ represents the length of evacuation road $a$ in units of $\mathrm{m} ; V_{a}$ represents the road capacity of evacuation road $a$ in units of pcu; $l_{a}$ represents the average length of evacuation vehicles running on road $a ; T_{e}$ represents the total evacuation time; $u_{a}(t)$ represents the rate of inflow on evacuation $\operatorname{road} a$ at time $t$ in units of $\mathrm{pcu} / \mathrm{s} ; v_{a}(t)$ represents the rate of outflow on evacuation road $a$ at time $t$ in units of pcu/s; $R_{a}^{t s}$ represents the space-time resource on evacuation $\operatorname{road} a ; C_{a}^{t s}$ represents the exhaustion of time and space on evacuation road $a$; and $\gamma$ represents the influence coefficient that affects road capacity and is determined by the Highway Capacity Manual (HCM2000).

Saturation is an important index to reflect traffic conditions. In the evacuation of large-scale activities, high traffic saturation may cause traffic jams that are adverse to traffic evacuation. Therefore, an acceptable saturation level should be ensured in the upper-level model and evacuation routes provided in the lower-level model under this restriction. The section flow conservation equation, capacity equation of evacuation routes, and space and time resource equation of evacuation routes are provided in (2) to (4), respectively.

The lower-level model 1 for large-scale activities can be established as

$$
\begin{array}{ll}
\min \quad Z_{1}=\sum_{a}\left(\int_{0}^{u_{a}(t)} I_{a}(t) d t+\sum_{t} \frac{V_{a}}{V_{a}(t)}\right) \\
\text { s.t } \quad x_{a}(t)=\sum_{r} \sum_{s} \sum_{p} \sum_{k_{p}} f_{k}^{r s} \delta_{a, k}^{r s} \quad \forall a \\
d_{k}^{r s}=\sum_{a} x_{a}^{s}(t) \delta_{a, k}^{r s} \\
\sum_{k} f_{k}^{r s}=T_{r s} \quad \forall r, s \\
c_{k}^{r s}=\sum_{a} \tau_{a}(t) \delta_{a, k}^{r s} \\
\tau_{a}(t)=\frac{\tau_{a}^{0}}{\alpha}\left[1+\left(\frac{x_{a}(t)}{C_{a}}\right)^{\beta}\right] \\
\tau_{a}(t) \geq 0 \\
f_{k}^{r s} \geq 0 \quad \forall k, r, s,
\end{array}
$$

where $Z_{1}$ represents the total evacuation time for normal large-scale activities; $I_{a}(t)$ represents the transient impedance on evacuation road $a$ at time $t$; $V_{a}$ represents the capacity of evacuation road $a$ in units of pcu; $v_{a}(t)$ represents the rate of outflow on evacuation road $a$ at time $t$ in units of $\mathrm{pcu} / \mathrm{s}$; $x_{a}(t)$ represents the number of vehicles on evacuation road $a$ at time $t ; f_{k}^{r s}$ represents the flow on path $k$ between $r$ and $s$ of OD point pairs in units of pcu; $\delta_{a, k}^{r s}$ indicates whether road $a$ belongs to path $k$ between $r$ and $s$ of OD point pairs, and if $a \in k$, then $\delta_{a, k}^{r s}=1$; otherwise, $\delta_{a, k}^{r s}=0 ; d_{k}^{r s}$ represents the traffic demand on path $k$ between $r$ and $s$ of OD point pairs in units of pcu; $T_{r s}$ represents the traffic volume between $r$ and $s$ of OD point pairs in units of pcu; $\tau_{a}(t)$ represents the average travel time through evacuation road $a$ at time $t ; \tau_{a}^{0}$ represents the travel time through evacuation road $a$ under free flow; and $\alpha$ and $\beta$ are both travel time parameters, with recommended values of 0.15 and 4 , respectively, in highway network applications.

Equations (6) to (8) are section flow conservation equations. The sum of flows between all the OD pairs is the total number of evacuation vehicles. Equations (9) and (10) represent the section travel time equations, and (11) and (12) are the nonnegative constraint equations.

The lower-level model 2 for emergencies in large-scale activities can be established as

$$
\begin{array}{ll}
\min & Z_{2}=\sum_{a} \sum_{t} u_{a}(t) I_{a}(t)+\sum_{a} \sum_{t} \frac{V_{a}}{V_{a}(t)} \\
\text { s.t } & \sum_{a} \sum_{t} u_{a}(t)=\frac{M_{a}}{\Delta t} \quad \forall a, t \\
& \frac{d x_{a}(t)}{d t}=u_{a}(t)-v_{a}(t) \quad \forall a, t \\
& u_{a}(t) \geq 0, \\
& v_{a}(t) \geq 0
\end{array}
$$

$\forall a, t$

$$
\begin{aligned}
& I_{a}(t) \\
& =\frac{L_{a}}{r_{a}^{\min }+\left(r_{a}^{\max }-r_{a}^{\min }\right)\left[1-\left(x_{a}(t) / V_{a}\right)^{\alpha}\right]^{\beta}} \quad \forall a, t \\
& V_{a}(t)=\frac{x_{a}(t)}{I_{a}(t)} \quad \forall a, t,
\end{aligned}
$$

where $Z_{2}$ represents the total evacuation time under induced emergencies; $u_{a}(t)$ represents the rate of inflow at time $t$ on evacuation road $a$ in units of pcu/s; $I_{a}(t)$ represents transient impedance at time $t$ on evacuation road $a ; V_{a}(t)$ represents the road capacity at time $t$ on evacuation road $a$ in units of pcu; $M_{a}$ represents the total number of evacuation vehicles on road $a ; \Delta t$ represents unit interval in units of $\mathrm{s} ; v_{a}(t)$ represents the rate of outflow at time $t$ on evacuation road $a$ in units of $\mathrm{pcu} / \mathrm{s} ; r_{a}^{\mathrm{min}}$ represents the minimum travel speed on evacuation road $a$; and $r_{a}^{\max }$ represents the free-flow travel speed on evacuation road $a$.

The evacuation time of individual vehicles is the sum of the waiting time at the starting point of evacuation and the travel time from the starting point to the ending point. The waiting time depends on the inflow rate $u_{a}(t)$. If $u_{a}(t)$ is larger, the waiting time will be shorter and vice versa. The inflow rate depends on the road volume, outflow rate, and traffic capacity. Therefore, the solution for the shortest evacuation time of 
the objective function is transformed to find the shortest travel time in the evacuation route when $u_{a}(t)$ is as large as possible.

2.2. Optimizing Condition of the Model. The Pontryagin maximum principle in optimizing control theory was used to solve the bilevel evacuation model. The general form of the conditions for the optimal solution of the upper-level model is expressed as

$$
\begin{aligned}
& H\left(v^{*}(t), u^{*}(t), \lambda^{*}(t), t\right) \leq H\left(v^{*}(t), u, \lambda^{*}(t), t\right) \\
& \psi_{r}(v(T))+H(T)=0 \\
& -\lambda^{\prime}(t)=H_{v}\left(v^{*}(t), u^{*}(t), \lambda^{*}(t), t\right) \\
& \quad=\lambda^{\prime}(t) f_{x}\left(v^{*}(t), u^{*}(t)\right)+L\left(v^{*}(t), u^{*}(t)\right) \\
& \lambda^{\prime}(T)=\psi(v(T))
\end{aligned}
$$

The Hamiltonian function was established based on the upper-level level as

$$
\begin{aligned}
H[ & v(t), u(t), \lambda(t)] \\
= & \sum_{a \in A} \frac{d_{k}^{r s}(t) T(t)_{e}}{3600 V_{a}(t) \cdot L_{a} \cdot l_{a} \cdot \gamma} \\
& +\sum_{a \in A} \sum_{n \in N} \lambda_{a}^{n}(t)\left[u_{a}^{n}(t)-v_{a}^{n}(t)\right] .
\end{aligned}
$$

The Euler-Lagrange equation was constructed as

$$
\begin{aligned}
& L[x(t), u(t), \lambda(t), \mu(t)] \\
& =H[x(t), u(t), \lambda(t)] \\
& \quad+\sum_{k \in N} \sum_{n \in N} \mu_{k}^{n}(t)\left[\frac{\sum_{a} R_{a}^{t s}(t)}{\sum_{a} C_{a}^{t s}(t) \cdot \lambda \sum_{a} L_{a}}-\sum_{a} V_{a}(t)\right] \\
& \quad+\sum_{n \in N} \mu_{n}^{n}(t) \sum_{a \in A(n)}\left[1-L_{a} \cdot \sum_{a} T_{e}(t)\right],
\end{aligned}
$$

where $\mu_{k}^{n}(t), \mu_{n}^{n}(t)$ are the Lagrange multipliers.

Thus, the objective function of the upper-level model can be written as

$$
\begin{aligned}
& Z_{0}=\psi(v(T))+\int_{0}^{T} L(v(t), u(t)) d t \\
& H(v(t), u(t), \lambda(t), t) \\
& \quad=\lambda^{\prime}(t) f(v(t), u(t))+L(v(t), u(t)) .
\end{aligned}
$$

Assuming $\left(x^{*}, u^{*}, v^{*}\right)$ as the optimal solution of the upper-level model, there exists $\left(\lambda^{*}, \mu^{*}\right)$ satisfying

$$
\begin{aligned}
& -\lambda_{a}^{* n}(t)=\frac{\partial L}{\partial v_{a}^{n}(t)} \\
& =-\left(\lambda_{a}^{* n}(t)-\mu_{a}^{* n}(t)\right) \frac{u_{a}^{n}(t)\left(d \tau_{a}(t) / d v_{a}(t)\right)}{\tau_{a}(t)}, \\
& -\lambda_{a}^{* n}(T)=0, \\
& \frac{\partial L}{\partial u_{a}^{n}(t)}=\lambda_{a}^{* n}(t) \geq 0, \\
& u_{a}^{n}(t) \frac{\partial L}{\partial u_{a}^{n}(t)}=u_{a}^{n}(t) \lambda_{a}^{* n}(t)=0, \\
& \frac{\partial L}{\partial \mu_{a}^{* n}(t)}=\sum_{a \in A} u_{a}^{n}(t)=0 .
\end{aligned}
$$

The lower-level model can be uniquely determined according to the optimal solution of the upper-level model. The optimizing conditions of the lower-level model can be deduced from the optimizing conditions of the upper-level model as

$$
\begin{aligned}
& \frac{\partial L}{\partial v_{a}} \longrightarrow \lambda_{a}^{n}(t)-\mu_{i}^{n}(t)=0, \\
& \frac{\partial L}{\partial u_{a}^{n}} \longrightarrow g\left(v_{a}(t)\right)=\lambda_{a} .
\end{aligned}
$$

\section{Algorithm Design}

The improved particle swarm optimization method was used to solve the bilevel planning model. The particle swarm optimization (PSO) method was first proposed by Kennedy and Eberhart in 1995. The PSO method is a group evolutionbased algorithm. The optimal solution for a complex problem is obtained based on the collaboration and competition of individuals. The classical PSO algorithm is to randomly form an initial particle swarm in the feasible solution space. Each particle represents a feasible solution. The objective function composes the fitness of the particle. During the evolution of particles, an individual particle will optimize itself only when its current position is better than the optimized individual. If the fitness of several particles is not better than the current optimum, there will be no update to individual optimization, which may reduce the convergence of the entire group, thus leading to premature convergence problems. Therefore, the traditional PSO method was improved in this study to make it more applicable for the traffic evacuation problem.

The electromagnetism-like mechanism (EM) was introduced in the PSO method (i.e., PSO-EM) to accelerate the convergence from the individual optimal to group optimal solution and reduce the possibility of stagnation of the individual optimal solution. Individual optimal solution of adjacent particles and group optimal solution act directly on the process of individual optimal solution through the absorption-rejection mechanism. The flowchart of the proposed PSO-EM algorithm is shown in Figure 1. 


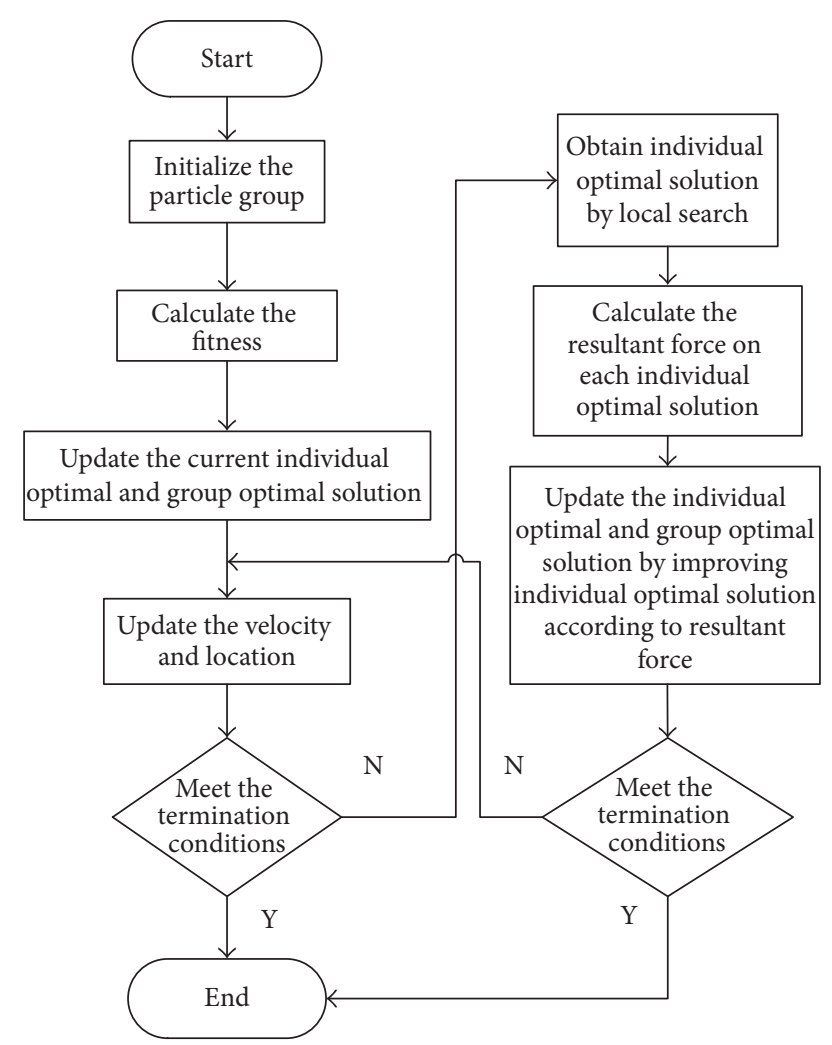

FIGURE 1: Flowchart of the proposed PSO-EM algorithm.

Figure 1 describes the process of the PSO-EM algorithm. The traditional PSO algorithm was first implemented. The EM algorithm was used for the individual optimal solution to calculate the resultant force of the particle. The resultant force was imposed by the individual optimal solution on all particles in this field. The individual optimal solution of particles was further improved by the absorption-rejection mechanism to enhance convergence speed. The detailed steps are presented as follows [23].

Step 1. Update the network information to obtain an initial feasible solution $X_{0}$ and the available evacuation routes in the traffic network.

Step 2. Initialize the velocity $V_{i}^{t}$ and location $X_{i}^{t}$ of particles $(i \in[1, m])$, where $m$ is the scale of the group and $t$ is the current iteration number. $P_{i}^{t}$ represents the current location of the $i$ th particle and $P_{g}$ the initial optimized location of the particle group. The initial solution of the lower-level model was obtained randomly.

Step 3. Update the velocity and location of particles according to $4-31$ and 4-32.

Step 4. Substitute the location of the $i$ th particle into the lower-level model and obtain the optimal solution $y_{i}^{\prime}, y_{i}^{\prime \prime}$ of the two lower-level models by traditional statistical methods. Substitute $X_{i}^{t}, y_{i}^{\prime}$ and $X_{i}^{t}, y_{i}^{\prime \prime}$ into the objective function of the upper-level model to recalculate the fitness of each particle fit $\left(X_{i}, y_{i}^{\prime}\right)$ and $\operatorname{fit}\left(X_{i}, y_{i}^{\prime \prime}\right)$ and update the individual optimal $P_{i}$ and group optimal $P_{g}$ :

$$
\begin{aligned}
& \text { fit }\left(X_{i}, y_{i}^{\prime}\right)=0.5-\frac{\sin ^{2} \sqrt{X_{i}^{2}+\left(y_{i}^{\prime}\right)^{2}}-0.5}{\left[1+0.001\left(X_{i}^{2}+\left(y_{i}^{\prime}\right)^{2}\right)\right]^{2}}, \\
& \text { fit }\left(X_{i}, y_{i}^{\prime \prime}\right)=0.5-\frac{\sin ^{2} \sqrt{X_{i}^{2}+\left(y_{i}^{\prime \prime}\right)^{2}}-0.5}{\left[1+0.001\left(X_{i}^{2}+\left(y_{i}^{\prime \prime}\right)^{2}\right)\right]^{2}} .
\end{aligned}
$$

Step 5. Update individual optimal $P_{i}$ by the EM algorithm.

Step 5.1. Obtain the new location of the individual optimal $P_{i}$ by local search and update $P_{i}(i=1,2, \ldots, m)$.

Step 5.2. Calculate the resultant force $F^{i}$ on each individual optimal $P_{i}$ using the following equations:

$$
\begin{aligned}
& q^{i}=\exp \left(-n \frac{f\left(P_{i}\right)-f\left(P_{g}\right)}{\sum_{k=1}^{m}\left(f\left(P_{k}\right)-f\left(P_{g}\right)\right)}\right), \\
& F^{i}=\sum_{j \neq i}^{m}\left\{\left(P_{j}-P_{i}\right) \frac{q^{i} q^{j}}{\left\|P_{j}-P_{i}\right\|^{2}}\right\} \quad \text { if } f\left(P_{j}\right)<f\left(P_{i}\right) \text {, } \\
& F^{i}= \begin{cases}\sum_{j \neq i}^{m}\left(P_{j}-P_{i}\right) \frac{q^{i} q^{j}}{\left\|P_{j}-P_{i}\right\|^{2}} & \text { if } f\left(P_{j}\right) \prec f\left(P_{i}\right) \\
\sum_{j \neq i}^{m}\left(P_{i}-P_{j}\right) \frac{q^{i} q^{j}}{\left\|P_{j}-P_{i}\right\|^{2}} & \text { if } f\left(P_{j}\right) \geq f\left(P_{i}\right) .\end{cases}
\end{aligned}
$$

Step 5.3. Move the individual optimal $P_{i}$ according to the equation below:

$$
P_{i}=P_{i}+\lambda \frac{F^{i}}{\left\|F^{i}\right\|}(\mathrm{RNG}) \quad i=1,2, \ldots, m
$$

where $\lambda$ is a random step which obeys the uniform distribution in $[0,1]$. RNG represents the allowable moving range toward the upper limit $u_{k}$ and lower limit $l_{k}$ :

$$
\begin{aligned}
\mathrm{RNG}= \begin{cases}u_{i k}-p_{i k} & \text { if } F_{k}^{i}>0 \\
p_{i k}-l_{i k} & \text { if } F_{k}^{i} \geq 0\end{cases} \\
\quad i=1,2, \ldots, m, k=1,2, \ldots, n .
\end{aligned}
$$

Step 6. Update the individual optimal $P_{i}$ and group optimal $P_{g}$ based on the results of Step 5.3.

Step 7. Determine whether the convergence criterion is satisfied:

$$
\zeta=\frac{\sqrt{\sum_{x \in X}\left(x_{i}^{t}-x_{i}^{t-1}\right)^{2}}}{\sum_{x \in X} x_{i}^{t-1}} \leq \zeta .
$$




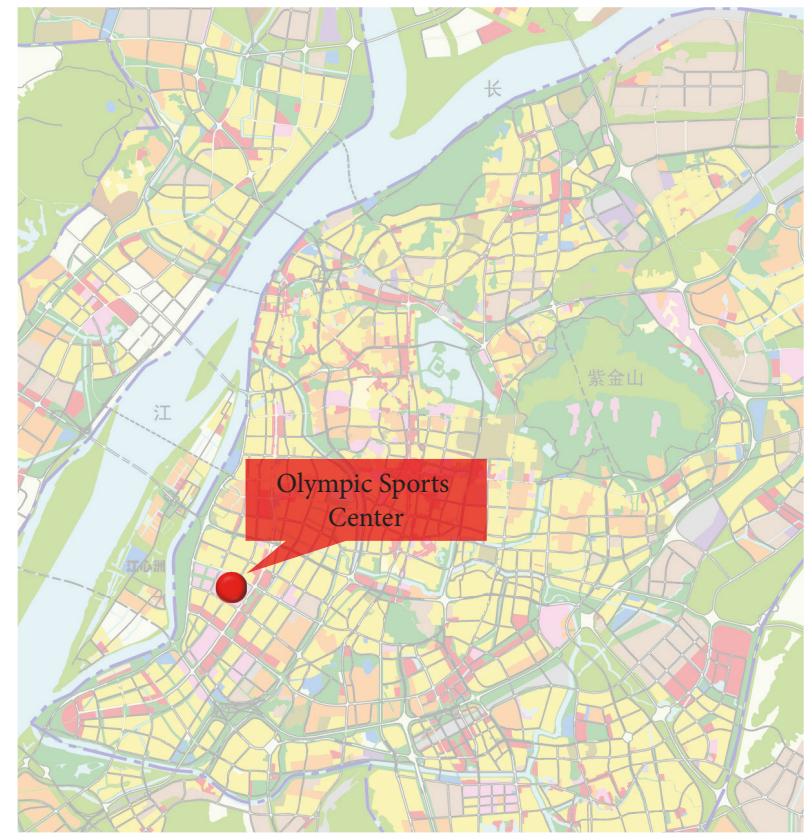

FIGURE 2: Location of the Nanjing Olympic Sports Center.

If yes, go to Step 8; otherwise, return to Step 5.

Step 8. Output the optimal solution of the bilevel model $P_{g}$ and $y_{i}^{\prime}, y_{i}^{\prime \prime}$, as well as the objective function value of the upper-level and lower-level planning models; then, end the algorithm.

\section{Case Study}

4.1. Region Selection. A case study was carried out on the Nanjing Olympic Sports Center; the surrounding road network and traffic demand were analyzed. The center is located in the southwest corner of Nanjing and in the area enclosed by Aoti Street, Jiangdong Zhong Road, Leshan Road, and Mengdu Street, as shown in Figure 2. The characteristics of the road network are listed in Table 1. The center is large, and the surrounding traffic network is complete, with good accessibility. Large-scale activities, such as sport games, conferences, and concerts, are often held in the center. This typical case was used to verify the proposed bilevel evacuation model.

The Nanjing Olympic Sports Center has a maximum capacity of fifty thousand people. Using the 11th city games held in July 2015 as an example, it was assumed that the audience attendance rates were 50\%,70\%, and $100 \%$, and all people attending were evacuated in these three cases. For the traffic network within a radius of $3 \mathrm{~km}$, there are a total of 39 road sections and 25 nodes, as shown in Figure 3. An evacuation simulation was conducted by assuming nodes 1 and 2 as the starting point of evacuation and nodes 18, 21, 23, and 25 as the ending points.

\subsection{Demand Analysis and Simulation Results}

4.2.1. Demand Analysis. Private vehicles and public transportation (including public bus and taxi) were considered in the evacuation simulation. According to the "annual report on traffic development in Nanjing in 2005," there are 1.2 million private vehicles, which equates to a car ownership rate per person of 0.065 . When the audience attendance rate was $100 \%$, the evacuation audience was 5,000 , and 3,250 private vehicles were needed. Assuming that one vehicle holds three individuals, a total of 9,750 individuals can be evacuated by private vehicles, and the remaining 40,250 are evacuated by public transportation.

According to the "annual report on traffic development in Nanjing in 2005," the proportions of individuals traveling by public bus and taxi are $72 \%$ and $28 \%$, respectively. Assume a capacity of 60 individuals per bus and 1.5 individuals per taxi, and consider the following equation:

$$
n_{i}=\frac{p \times \phi_{i}}{f_{i}}
$$

where $n_{i}$ is the number of the $i$ th type of vehicle; $p$ is the number of evacuated individuals; $\phi_{i}$ is the ratio of individuals choosing the $i$ th-type vehicle; and $f_{i}$ is the capacity per vehicle for the $i$ th-type vehicle.

From the above equation, a total of 320 buses and 980 taxis are needed to evacuate 40,250 individuals. A total of 4,870 vehicles are needed to evacuate the fifty thousand attendees. Similarly, 2,435 and 3,409 vehicles are needed for the evacuation when $50 \%$ and $70 \%$ of the audience are present, respectively. 
TABLE 1: Characteristics of the traffic network surrounding the Nanjing Olympic Sports Center.

\begin{tabular}{|c|c|c|c|c|c|c|c|}
\hline $\begin{array}{l}\text { Starting } \\
\text { point }\end{array}$ & $\begin{array}{c}\text { Ending } \\
\text { point }\end{array}$ & $\begin{array}{l}\text { Length } \\
(\mathrm{m})\end{array}$ & $\begin{array}{c}\text { Designed } \\
\text { vehicle } \\
\text { speed } \\
(\mathrm{km} / \mathrm{h})\end{array}$ & $\begin{array}{c}\text { Starting } \\
\text { point }\end{array}$ & $\begin{array}{c}\text { Ending } \\
\text { point }\end{array}$ & $\begin{array}{l}\text { Length } \\
(\mathrm{m})\end{array}$ & $\begin{array}{c}\text { Designed } \\
\text { vehicle } \\
\text { speed } \\
(\mathrm{km} / \mathrm{h})\end{array}$ \\
\hline 1 & 2 & 1205 & 80 & 14 & 15 & 1169 & 80 \\
\hline 1 & 3 & 776 & 60 & 15 & 16 & 1501 & 80 \\
\hline 2 & 4 & 847 & 80 & 6 & 22 & 1245 & 60 \\
\hline 3 & 4 & 1112 & 60 & 1 & 13 & 1230 & 60 \\
\hline 1 & 6 & 905 & 80 & 2 & 14 & 1587 & 60 \\
\hline 3 & 7 & 656 & 60 & 5 & 15 & 1644 & 60 \\
\hline 2 & 5 & 946 & 80 & 11 & 16 & 1745 & 80 \\
\hline 5 & 11 & 1425 & 80 & 18 & 19 & 997 & 80 \\
\hline 4 & 12 & 2231 & 60 & 19 & 20 & 883 & 80 \\
\hline 6 & 7 & 818 & 60 & 20 & 21 & 1563 & 60 \\
\hline 11 & 12 & 1208 & 80 & 9 & 18 & 1237 & 60 \\
\hline 9 & 8 & 1355 & 60 & 8 & 19 & 1550 & 60 \\
\hline 8 & 10 & 841 & 60 & 10 & 20 & 1832 & 60 \\
\hline 10 & 17 & 1439 & 60 & 17 & 21 & 1423 & 80 \\
\hline 7 & 9 & 786 & 60 & 23 & 24 & 1308 & 60 \\
\hline 4 & 8 & 905 & 60 & 24 & 25 & 1355 & 60 \\
\hline 5 & 10 & 1967 & 60 & 22 & 23 & 942 & 60 \\
\hline 12 & 17 & 951 & 80 & 14 & 24 & 1244 & 60 \\
\hline 13 & 22 & 998 & 80 & 15 & 25 & 1910 & 60 \\
\hline 13 & 14 & 1309 & 80 & & & & \\
\hline
\end{tabular}

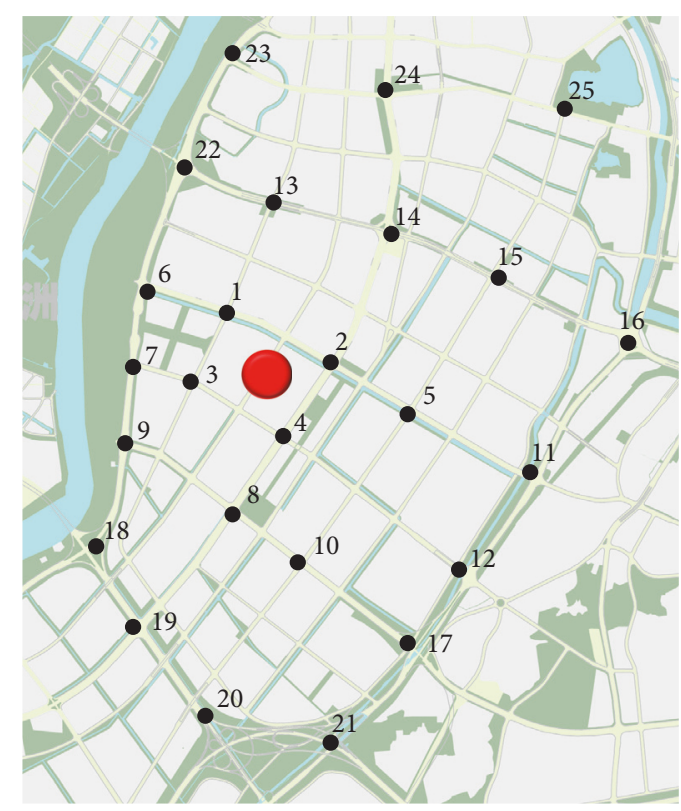

FIGURE 3: Surrounding road sections and nodes of Nanjing Olympic Sports Center.

4.2.2. Simulation Results. The proposed model was compared to classical traffic distribution algorithms. The evacuated traffic flow, road saturation, and evacuation time of the 12 shortest routes (reaching ending points 15-18) were compared using the three attendance rates.
(1) Classical Traffic Distribution Model. Based on the traffic simulation software TRANSCAD's function of traditional traffic distribution, the necessary evacuation vehicles were distributed to the surrounding road network through the gravity application model, as listed in Table 2. 
(2) Bilevel Evacuation Model. A total of 2,800 particles were selected based on the PSO method. The proposed bilevel evacuation model converged after 14, 15, and 21 iterations, respectively. The traffic distribution from the proposed model is shown in Tables 3, 4, and 5.

4.3. Comparison of the Results. Figures 4-6 are plotted based on the results in Tables 3, 4, and 5.

Results in Tables 2-5 show that the proposed bilevel evacuation model has better reality, feasibility, and efficiency:

(1) The classical traffic distribution is a uniform distribution with a bidirectional traffic flow and obeys the shortest traveling route principle. In contrast, the traffic distribution of a large-scale activity is single-source and multiroute traffic. It is a one-way traffic flow when not considering the road traffic background. There are many subjective factors and strong instability in the large-scale activities. The occurrence of emergencies may affect the normal traffic evacuation strategy and even disturb normal traffic. Therefore, this paper adopted two evacuation mechanisms to consider the two traffic conditions. For the normal activity, the model ensured the servicing level of the traffic network because the evacuation time was not tight. Once emergencies occurred, the emergency plan was initiated and the lower-level model 2 was used, with the shortest evacuation time taken as the optimizing objective.

(2) Significant differences in the road saturation distribution exist between the two models. For normal large-scale activities, the road saturation standard deviations of the classical model under the audience attendance rates of $50 \%, 70 \%$, and $100 \%$ are 9.2 , 13.5 , and 15.8 , respectively, whereas the corresponding values of the bilevel planning model are 7.6, 9.9, and 7.9; these values are $17 \%, 26 \%$, and $49 \%$ lower than the former values. The saturation distribution inequality decreases with increasing audience attendance rate, mainly because the classical model is based on road impedance and the traffic distribution process; thus, it tends to distribute traffic to the path of the lowimpedance factor and short distance without considering the relationship between the road passing capacity and volume, among others. Taking condition $\mathrm{C}$ in Table 2 as an example, the saturation of path 5 reached $83.1 \%$, whereas the saturation of path 1 is only $31.8 \%$. The saturation distribution inequality will cause path 5 to be crowded and path 1 to be free, which does not make full use of network resources and thus reduces the network's overall evacuation efficiency. However, the bilevel planning model considering the indexes of road network saturation can fully use the entire evacuation capacity of the network to lower the road saturation and increase vehicle speed, thereby improving the evacuation efficiency. The degree of improvement of the standard deviation increased gradually with increases in the audience attendance rate, indicating that if the evacuation scale is larger, the utilization degree of the surrounding road network will be larger and evacuation efficiency of the bilevel planning model will be higher.

(3) For normal large-scale activities, the average evacuation time of the classical model is shorter than that for the bilevel planning model. The average evacuation time of the classical model under audience attendance rates of $50 \%, 70 \%$, and $100 \%$ were 6.0 , 6.7, and 9.4 minutes, respectively, whereas the values of the bilevel planning model were 6.1, 7.3, and 12.1 minutes, significantly higher than the former values. This discrepancy mainly occurs because the classical traffic model is based on the principle of minimum impedance; thus, it first assigned vehicles to the shortest road section that can shorten the evacuation time effectively. However, this will cause such problems as an uneven distribution of traffic volume and greater differences in the evacuation time of paths. Differing from the classical model, the bilevel planning model considers such factors as path saturation and path impedance at the same time. Although the average evacuation time is slightly longer, the difference in evacuation time of each path is decreased to improve evacuation efficiency of the entire road network.

(4) For induced emergencies, the evacuation time of the bilevel planning model is considerably shorter than that for the classical model. For normal largescale activities, the longest evacuation times under audience attendance rates of $50 \%, 70 \%$, and $100 \%$ were $9.8,12.3$, and 18.1 minutes, respectively. However, for induced emergencies, the values were 7.6, 9.3, and 11.6 minutes, respectively, or $22 \%, 22 \%$, and $24 \%$ lower than the corresponding former values. In the model for induced emergencies, the waiting time of vehicles driven from the venue to the evacuation starting point is mainly reduced by increasing the vehicle flow rate into the network, thus shortening the overall evacuation time. Thus, the model can satisfy the dual evacuation requirements of both large-scale activities and induced emergencies. The degree of shortening of the evacuation time will be greater for higher audience attendance rates. This trend indicates that the bilevel planning model is suitable for largescale evacuation under induced emergencies, which further proves the feasibility and validity of the model.

(5) The algorithm efficiency of the bilevel planning model is higher than that of the classical model. The road network chosen in this study has a radius of $3 \mathrm{~km}$, 25 nodes, and 39 road sections. The computation cost for this region is high. The proposed algorithm used 2,800 particles and obtained convergence after 14, 15 , and 21 iterations, respectively. Therefore, the proposed algorithm can enhance the efficiency and feasibility of the traffic distribution for a reasonable scale.

\section{Conclusions}

This paper proposed a bilevel evacuation model with one master and multiple slaves to solve the traffic evacuation 
TABLE 2: Traffic distribution results obtained with the classical method.

\begin{tabular}{|c|c|c|c|c|c|c|c|c|c|c|}
\hline \multirow{2}{*}{$\begin{array}{l}\text { Number } \\
\text { of } \\
\text { routes }\end{array}$} & \multicolumn{3}{|c|}{$\begin{array}{c}\text { Evacuated traffic } \\
\text { volume } \\
(\mathrm{pcu})\end{array}$} & \multicolumn{3}{|c|}{$\begin{array}{c}\text { Road saturation } \\
(\%)\end{array}$} & \multicolumn{3}{|c|}{$\begin{array}{l}\text { Evacuation time } \\
(\min )\end{array}$} & \multirow{2}{*}{$\begin{array}{c}\begin{array}{c}\text { Detailed } \\
\text { evacuation route }\end{array} \\
--\end{array}$} \\
\hline & A & $\mathrm{B}$ & $\mathrm{C}$ & A & B & $\mathrm{C}$ & A & B & $\mathrm{C}$ & \\
\hline 1 & 61 & 79 & 105 & 12.0 & 19.5 & 23.3 & 3.5 & 4.5 & 5.8 & $1-6-7-9-18$ \\
\hline 2 & 72 & 110 & 154 & 26.8 & 33.4 & 41.9 & 4.2 & 4.0 & 5.1 & 1-3-9-18 \\
\hline 3 & 188 & 231 & 315 & 44.1 & 58.3 & 70.6 & 7.5 & 9.1 & 12.5 & $1-2-5-11-12-17-21$ \\
\hline 4 & 175 & 222 & 289 & 35.8 & 51.6 & 62.8 & 6.2 & 7.3 & 10.4 & $1-2-4-8-19-20-21$ \\
\hline 5 & 214 & 309 & 428 & 49.9 & 70.2 & 83.1 & 11.1 & 13.0 & 18.5 & $1-6-22-23$ \\
\hline 6 & 144 & 210 & 288 & 35.6 & 48.9 & 59.3 & 2.6 & 3.3 & 4.3 & $1-13-23$ \\
\hline 7 & 168 & 235 & 336 & 41.4 & 56.8 & 75.7 & 6.9 & 7.8 & 9.9 & $1-2-5-15-25$ \\
\hline 8 & 168 & 244 & 357 & 44.3 & 55.4 & 73.9 & 4.7 & 5.5 & 7.8 & $1-13-14-24-25$ \\
\hline 9 & 121 & 199 & 262 & 25.8 & 26.3 & 35 & 5.5 & 4.6 & 6.6 & $2-1-6-7-9-18$ \\
\hline 10 & 156 & 255 & 364 & 44.8 & 60.0 & 77.1 & 6.1 & 4.8 & 10.2 & $2-4-8-19-18$ \\
\hline 11 & 204 & 267 & 408 & 42.7 & 63.6 & 80.8 & 11.8 & 15.7 & 19.6 & $2-5-11-12-17-21$ \\
\hline 12 & 133 & 201 & 266 & 36.8 & 46.0 & 61.3 & 6.2 & 6.3 & 10.4 & $2-5-10-20-21$ \\
\hline 13 & 168 & 229 & 350 & 38.9 & 54.3 & 72.4 & 3.7 & 3.9 & 6.2 & $2-1-6-22-23$ \\
\hline 14 & 152 & 213 & 304 & 41.7 & 52.1 & 69.5 & 4.4 & 3.9 & 5.9 & $2-14-24-23$ \\
\hline 15 & 183 & 245 & 389 & 40.1 & 56.7 & 75.6 & 7.4 & 8.3 & 11.5 & $2-5-15-25$ \\
\hline 16 & 128 & 160 & 255 & 34.9 & 43.6 & 58.1 & 3.5 & 4.6 & 5.8 & 2-14-24-25 \\
\hline
\end{tabular}

Note. "A" represents a 50\% audience attendance; "B" represents a 70\% audience attendance rate; and "C" represents a $100 \%$ audience attendance rate.

TABLE 3: Traffic distribution of the proposed bilevel model (A: $50 \%$ audience attendance rate).

\begin{tabular}{|c|c|c|c|c|c|c|c|}
\hline \multirow{2}{*}{$\begin{array}{l}\text { Number of } \\
\text { routes }\end{array}$} & \multicolumn{2}{|c|}{$\begin{array}{c}\text { Evacuated traffic } \\
\text { volume } \\
(\mathrm{pcu})\end{array}$} & \multicolumn{2}{|c|}{$\begin{array}{c}\text { Road saturation } \\
(\%)\end{array}$} & \multicolumn{2}{|c|}{$\begin{array}{l}\text { Evacuation time } \\
(\mathrm{min})\end{array}$} & \multirow{2}{*}{$\begin{array}{c}\text { Detailed } \\
\text { evacuation route }\end{array}$} \\
\hline & $\begin{array}{c}\text { Normal } \\
\text { case }\end{array}$ & $\begin{array}{c}\text { Induced } \\
\text { emergencies }\end{array}$ & $\begin{array}{c}\text { Normal } \\
\text { case }\end{array}$ & $\begin{array}{c}\text { Induced } \\
\text { emergencies }\end{array}$ & $\begin{array}{c}\text { Normal } \\
\text { case }\end{array}$ & $\begin{array}{c}\text { Induced } \\
\text { emergencies }\end{array}$ & \\
\hline 1 & 92 & 125 & 18.1 & 21.5 & 5.5 & 4.3 & $1-6-7-9-18$ \\
\hline 2 & 105 & 127 & 32.5 & 35.7 & 4.8 & 4.6 & $1-3-9-18$ \\
\hline 3 & 143 & 134 & 40.6 & 43.8 & 6.9 & 5.9 & $1-2-5-11-12-17-21$ \\
\hline 4 & 183 & 174 & 36.3 & 40.7 & 6.1 & 5.3 & $1-2-4-8-19-20-21$ \\
\hline 5 & 235 & 232 & 50.1 & 52.4 & 9.8 & 7.4 & $1-6-22-23$ \\
\hline 6 & 145 & 144 & 36.6 & 35.6 & 3.5 & 4.1 & $1-13-23$ \\
\hline 7 & 156 & 152 & 39.3 & 40.5 & 6.6 & 5.5 & $1-2-5-15-25$ \\
\hline 8 & 152 & 143 & 45.2 & 47.8 & 4.5 & 3.2 & $1-13-14-24-25$ \\
\hline 9 & 130 & 137 & 26.8 & 35.1 & 5.3 & 4.7 & $2-1-6-7-9-18$ \\
\hline 10 & 102 & 115 & 42.7 & 36.6 & 5.2 & 3.6 & $2-4-8-19-18$ \\
\hline 11 & 234 & 215 & 43.5 & 39.7 & 8.7 & 7.6 & $2-5-11-12-17-21$ \\
\hline 12 & 154 & 144 & 39.1 & 48.2 & 5.9 & 4.8 & $2-5-10-20-21$ \\
\hline 13 & 127 & 124 & 35.4 & 36.2 & 4.4 & 5 & $2-1-6-22-23$ \\
\hline 14 & 140 & 132 & 41.3 & 49.6 & 5.2 & 4.8 & $2-14-24-23$ \\
\hline 15 & 195 & 187 & 42.2 & 48.2 & 8.8 & 6.9 & $2-5-15-25$ \\
\hline 16 & 142 & 150 & 38.8 & 38.7 & 6.9 & 5.2 & $2-14-24-25$ \\
\hline
\end{tabular}


TABLE 4: Traffic distribution of the proposed bilevel model (B: 70\% audience attendance rate).

\begin{tabular}{|c|c|c|c|c|c|c|c|}
\hline \multirow{2}{*}{$\begin{array}{l}\text { Number of } \\
\text { routes }\end{array}$} & \multicolumn{2}{|c|}{$\begin{array}{c}\text { Evacuated traffic } \\
\text { volume } \\
(\mathrm{pcu})\end{array}$} & \multicolumn{2}{|c|}{$\begin{array}{c}\text { Road saturation } \\
(\%)\end{array}$} & \multicolumn{2}{|c|}{$\begin{array}{l}\text { Evacuation time } \\
\qquad(\min )\end{array}$} & \multirow{2}{*}{$\begin{array}{c}\text { Detailed } \\
\text { evacuation route }\end{array}$} \\
\hline & $\begin{array}{c}\text { Normal } \\
\text { case }\end{array}$ & $\begin{array}{c}\text { Induced } \\
\text { emergencies }\end{array}$ & $\begin{array}{l}\text { Normal } \\
\text { case }\end{array}$ & $\begin{array}{c}\text { Induced } \\
\text { emergencies }\end{array}$ & $\begin{array}{c}\text { Normal } \\
\text { case }\end{array}$ & $\begin{array}{c}\text { Induced } \\
\text { emergencies }\end{array}$ & \\
\hline 1 & 112 & 157 & 29.4 & 37.4 & 5.9 & 3.6 & $1-6-7-9-18$ \\
\hline 2 & 132 & 164 & 35.7 & 39.2 & 5.5 & 4.2 & $1-3-9-18$ \\
\hline 3 & 210 & 223 & 60.2 & 58.3 & 8.7 & 6.8 & $1-2-5-11-12-17-21$ \\
\hline 4 & 211 & 197 & 48.3 & 50.2 & 7.4 & 6.1 & $1-2-4-8-19-20-21$ \\
\hline 5 & 276 & 298 & 61.6 & 77.9 & 11.1 & 9.3 & $1-6-22-23$ \\
\hline 6 & 253 & 275 & 49.4 & 60.1 & 6.3 & 5.2 & 1-13-23 \\
\hline 7 & 248 & 227 & 54.1 & 57.2 & 7.2 & 4.3 & $1-2-5-15-25$ \\
\hline 8 & 239 & 206 & 51.9 & 50.7 & 6.1 & 3.9 & $1-13-14-24-25$ \\
\hline 9 & 207 & 195 & 34.7 & 41.2 & 5.2 & 5 & $2-1-6-7-9-18$ \\
\hline 10 & 243 & 252 & 61.6 & 65.3 & 6.6 & 5.7 & $2-4-8-19-18$ \\
\hline 11 & 250 & 236 & 56.1 & 65.8 & 12.3 & 9.3 & $2-5-11-12-17-21$ \\
\hline 12 & 189 & 167 & 45.5 & 47.2 & 7.7 & 5.4 & $2-5-10-20-21$ \\
\hline 13 & 202 & 237 & 58.2 & 63.7 & 5.5 & 4.5 & $2-1-6-22-23$ \\
\hline 14 & 265 & 239 & 50.6 & 53.6 & 8.4 & 5.8 & $2-14-24-23$ \\
\hline 15 & 217 & 189 & 55.5 & 60.8 & 8.2 & 7.1 & $2-5-15-25$ \\
\hline 16 & 155 & 147 & 41.9 & 55.3 & 5.3 & 4.2 & 2-14-24-25 \\
\hline
\end{tabular}

TABLE 5: Traffic distribution of the proposed bilevel model (C: 100\% audience attendance rate).

\begin{tabular}{|c|c|c|c|c|c|c|c|}
\hline \multirow{2}{*}{$\begin{array}{l}\text { Number of } \\
\text { routes }\end{array}$} & \multicolumn{2}{|c|}{$\begin{array}{c}\text { Evacuated traffic } \\
\text { volume } \\
(\mathrm{pcu})\end{array}$} & \multicolumn{2}{|c|}{$\begin{array}{c}\text { Road saturation } \\
(\%)\end{array}$} & \multicolumn{2}{|c|}{$\begin{array}{l}\text { Evacuation time } \\
(\min )\end{array}$} & \multirow{2}{*}{$\begin{array}{c}\text { Detailed } \\
\text { evacuation route }\end{array}$} \\
\hline & $\begin{array}{c}\text { Normal } \\
\text { case }\end{array}$ & $\begin{array}{c}\text { Induced } \\
\text { emergencies }\end{array}$ & $\begin{array}{l}\text { Normal } \\
\text { case }\end{array}$ & $\begin{array}{c}\text { Induced } \\
\text { emergencies }\end{array}$ & $\begin{array}{l}\text { Normal } \\
\text { case }\end{array}$ & $\begin{array}{c}\text { Induced } \\
\text { emergencies }\end{array}$ & \\
\hline 1 & 248 & 332 & 47.5 & 78.3 & 9.4 & 4 & $1-6-7-9-18$ \\
\hline 2 & 309 & 281 & 61.4 & 75.2 & 10.2 & 5.5 & 1-3-9-18 \\
\hline 3 & 326 & 405 & 63.4 & 70.3 & 16.5 & 7.4 & $1-2-5-11-12-17-21$ \\
\hline 4 & 344 & 307 & 73.7 & 81.2 & 15.7 & 8.7 & $1-2-4-8-19-20-21$ \\
\hline 5 & 419 & 328 & 75.6 & 80 & 9.3 & 4.4 & $1-6-22-23$ \\
\hline 6 & 328 & 320 & 60.9 & 71.1 & 6.7 & 3.1 & 1-13-23 \\
\hline 7 & 272 & 246 & 59.3 & 68.8 & 10.5 & 4.6 & $1-2-5-15-25$ \\
\hline 8 & 352 & 321 & 68.5 & 70.5 & 15 & 6.2 & $1-13-14-24-25$ \\
\hline 9 & 257 & 325 & 49.3 & 65.4 & 10.9 & 5 & $2-1-6-7-9-18$ \\
\hline 10 & 265 & 238 & 57.5 & 67.7 & 11.2 & 5.1 & $2-4-8-19-18$ \\
\hline 11 & 324 & 312 & 74.1 & 88.6 & 18.1 & 11.6 & $2-5-11-12-17-21$ \\
\hline 12 & 333 & 229 & 62.3 & 68.8 & 16.7 & 7.8 & $2-5-10-20-21$ \\
\hline 13 & 250 & 306 & 56.6 & 65.5 & 10.2 & 4.9 & $2-1-6-22-23$ \\
\hline 14 & 322 & 260 & 61.6 & 72.9 & 10.1 & 4.6 & $2-14-24-23$ \\
\hline 15 & 258 & 238 & 60.8 & 72.3 & 13.5 & 5.8 & $2-5-15-25$ \\
\hline 16 & 263 & 422 & 62.6 & 80.7 & 10.8 & 5.2 & $2-14-24-25$ \\
\hline
\end{tabular}




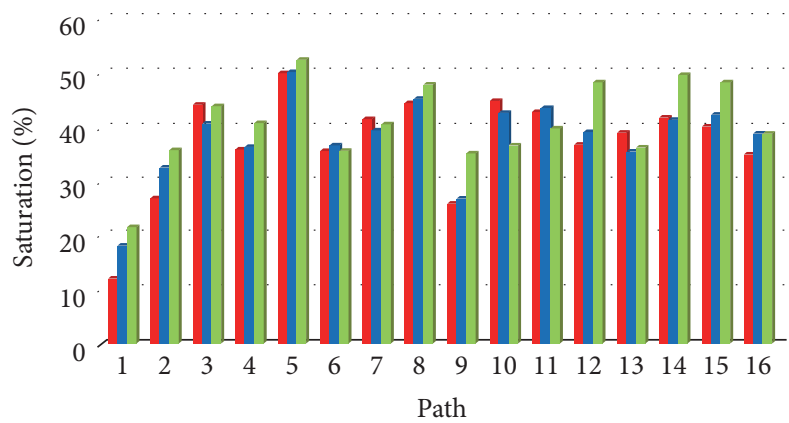

- Classical distribution model

- Bilevel evacuation model-normal case

- Bilevel evacuation model-induced emergency

(a) Path saturation

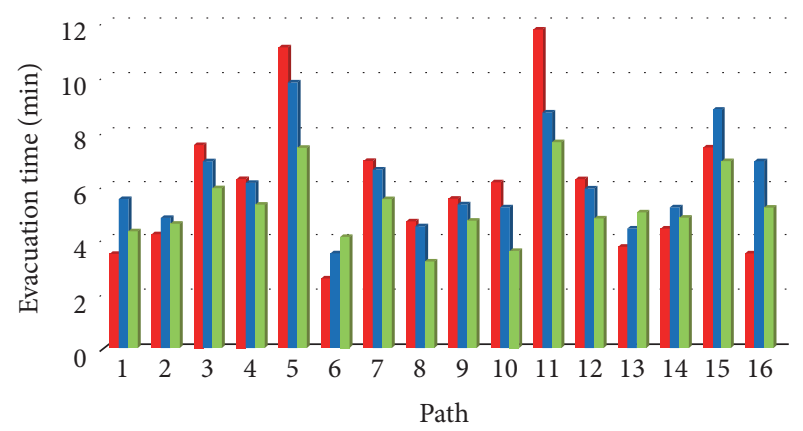

- Classical distribution model

- Bilevel evacuation model-normal case

- Bilevel evacuation model-induced emergency

FIGURE 4: Comparison of model results (50\% audience attendance rate).

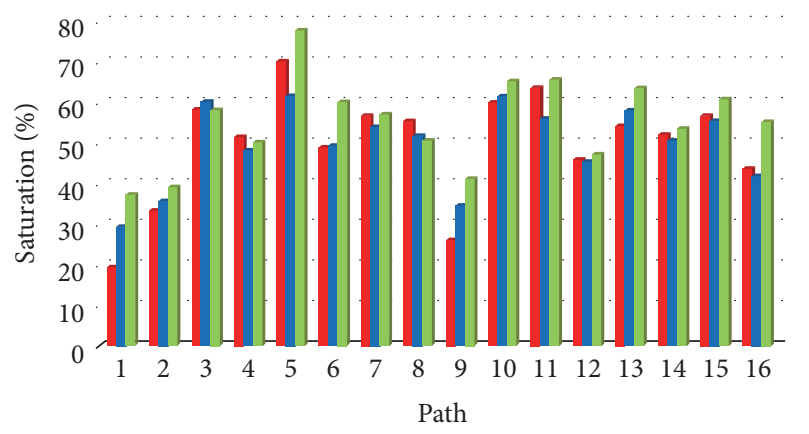

- Classical distribution model

- Bilevel evacuation model-normal case

- Bilevel evacuation model-induced emergency

(a) Path saturation

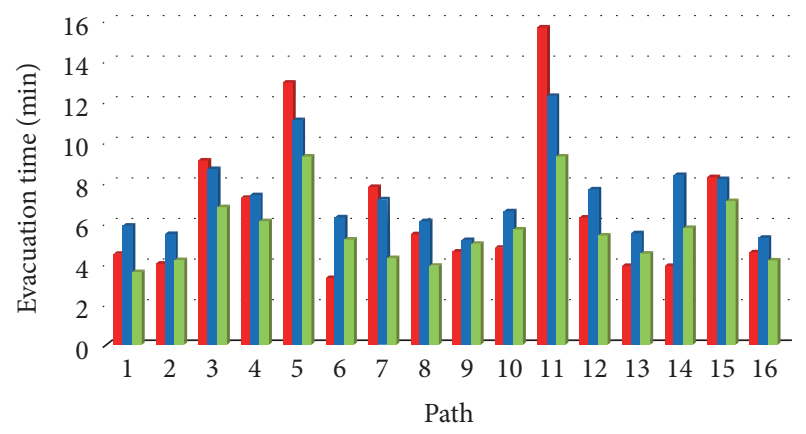

- Classical distribution model

- Bilevel evacuation model-normal case

- Bilevel evacuation model-induced emergency

FIGURE 5: Comparison of model results (70\% audience attendance rate).

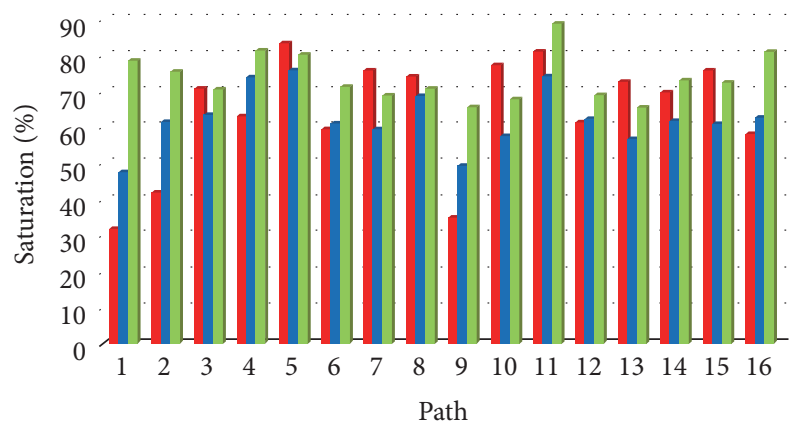

- Classical distribution model

- Bilevel evacuation model-normal case

- Bilevel evacuation model-induced emergency

(a) Path saturation

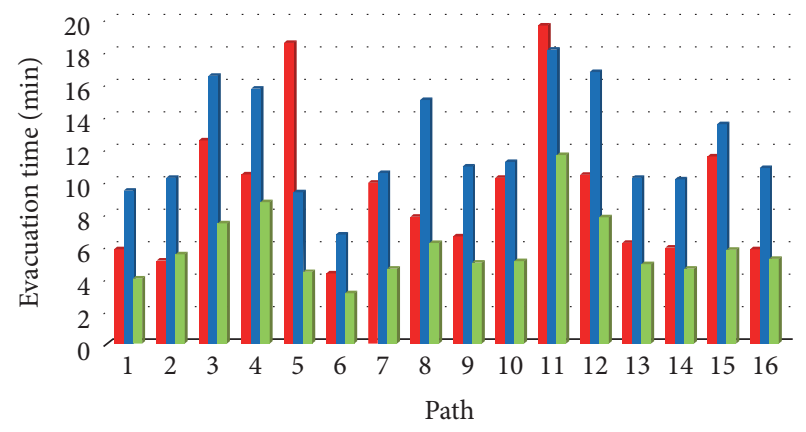

- Classical distribution model

- Bilevel evacuation model-normal case

- Bilevel evacuation model-induced emergency

(b) Evacuation time

FIGURE 6: Comparison of model results (100\% audience attendance rate). 
problems for large-scale activities and induced emergencies. The upper-level model used the minimum road saturation as the objective function, whereas the lower-level model applied the minimum evacuation time as the objective function. The optimizing conditions were analyzed. The improved PSO method was used to solve the bilevel model. The electromagnetism-like mechanism (EM) was introduced in the PSO method to accelerate convergence speed and avoid the premature convergence problem.

Second, a case study was carried out on the 11th city games held in the Nanjing Olympic Sports Center. Based on the surrounding traffic network and traffic evacuation demand, the proposed model was used to solve the evacuation plans for this event and potential emergencies under three audience attendance rates, and the results were compared with those from the classical gravity application method. The case analysis results indicated that, under normal large-scale activities, the average evacuation time of the classical model is shorter, but the road section saturation distribution disparity is increased with the proposed model. This result is mainly because the classical model is based on the road impedance and traffic distribution; it tends to distribute traffic to the path of small impedance and shortest distance without considering the relationship between road passing capacity and volume, among others. However, the bilevel planning model considering the indexes of road network saturation can fully use the entire evacuation capacity of the network to lower the road saturation, thereby improving the evacuation efficiency. For induced emergencies, the evacuation time of the bilevel planning model is considerably shorter than that of the classical model. The evacuation time is shortened by $22 \%$ to $35 \%$ with increases in the audience attendance rate, indicating that the optimization effect of the model is greater when the audience is larger. In the model for induced emergencies, the waiting time of vehicles driven from the venue to the evacuation starting point is reduced by increasing the vehicle flow rate into the network, thus shortening the overall evacuation time. From the perspective of model algorithm efficiency, the improved PSO algorithm had high efficiency and obtained the optimal solution after 14,15 , and 21 iterations for audience attendance rates of $50 \%, 70 \%$, and $100 \%$, respectively. The proposed model and algorithm provide technical support for the evacuation of large-scale activities.

Further work is needed to study the evacuation ratio and assess the induced evacuation effect, which may affect the global evacuation of large-scale activities.

\section{Conflicts of Interest}

The authors declare that there are no conflicts of interest regarding the publication of this paper.

\section{Acknowledgments}

This research was sponsored by the National Natural Science Foundation of China (Grant no. 51508274) and the Natural Science Foundation of Jiangsu Province (BK20140821). The authors also would like to thank the College of Civil Aviation of Nanjing University of Aeronautics and Astronautics for their contribution to the survey.

\section{References}

[1] R. Amodei, E. Bard, B. Brong et al., "1996 Atlanta Centennial Olympic Games and Paralympic Games Event Study," Tech. Rep. FHWA-RD-97-107, US Department of Transportation Federal Highway Administration, 1997.

[2] ORTA, Nothing better than this (Transport for the Sydney 2000 Olympic and Paralympics Games), ORTA, Sydney, Australia, 2001.

[3] L. J. Glazer and R. Cruz, Intelligent Transportation Systems at the 2002 Salt Lake City Winter Olympic Games, Iteris, Inc., Anaheim, Calif, USA, 2004.

[4] Athens 2004 Transportation Authority, Athens 2004 Olympic Games Transportation Plan, 2002.

[5] FHWA, Managing Travel for Planned Special Events, FHWA, Washington DC, Wash, USA, 2003.

[6] Beijing University of Technology, Traffic Planning for Olympic Games, Beijing University of Technology, Beijing, China, 2005.

[7] X. Chen, J. Wu, and H. Lin, "Traffic management mode and traffic organization scheme in the 2010 Shanghai world expo control area," Traffic and Transportation, vol. 24, no. 6, pp. 10-12, 2008.

[8] K. Yan, "Several recommendations to further and detailed the traffic organization plan of Expo," Traffic and Transportation, vol. 26, no. 1, pp. 4-6, 2010.

[9] X. Ma, “The 2010 Guangzhou Asian Games traffic development strategic planning," Journal of Transportation Systems Engineering and Information Technology, vol. 8, no. 04, pp. 16-22, 2008.

[10] X. Long and P. Yan, "The 2010 Guangzhou Asian Games traffic management measures," China Transportation Review, vol. 5, no. 7, pp. 61-65, 2009.

[11] Y. Liu, X. Lai, and G.-L. Chang, "Two-level integrated optimization system for planning of emergency evacuation," Journal of Transportation Engineering, vol. 132, no. 10, pp. 800-807, 2006.

[12] Y.-C. Chiu, H. Zheng, J. Villalobos, and B. Gautam, "Modeling no-notice mass evacuation using a dynamic traffic flow optimization model," Institute of Industrial Engineers, vol. 39, no. 1, pp. 83-94, 2007.

[13] H. X. Liu, J. X. Ban, W. Ma, and P. B. Mirchandani, "Model reference adaptive control framework for real-time traffic management under emergency evacuation," Journal of Urban Planning and Development, vol. 133, no. 1, pp. 43-50, 2007.

[14] M. A. Yazici and K. Ozbay, "Impact of probabilistic road capacity constraints on the spatial distribution of hurricane evacuation shelter capacities," Transportation Research Record, no. 2022, pp. 55-62, 2007.

[15] X. Yan, N. Lv, Z. Liu et al., "Bi-level programming of the lane line optimization after large events," Journal of Southwest Jiaotong University, vol. 44, no. 1, pp. 112-117, 2009.

[16] K. Doan and S. V. Ukkusuri, "On the holding-back problem in the cell transmission based dynamic traffic assignment models," Transportation Research Part B: Methodological, vol. 46, no. 9, pp. 1218-1238, 2012.

[17] A. C. Y. Li, L. Nozick, R. Davidson, N. Brown, D. A. Jones, and B. Wolshon, "Approximate solution procedure for dynamic traffic assignment," Journal of Transportation Engineering, vol. 139, no. 8, pp. 822-832, 2013. 
[18] B. D. Chung, T. Yao, and B. Zhang, "Dynamic traffic assignment under uncertainty: a distributional robust chance-constrained approach," Networks and Spatial Economics, vol. 12, no. 1, pp. 167-181, 2012.

[19] H. Naghawi and B. Wolshon, "Performance of traffic networks during multimodal evacuations: simulation-based assessment," Natural Hazards Review, vol. 13, no. 3, pp. 196-204, 2012.

[20] X. Zhao, G. Ren, C. Fan, and C.-Z. Ding, "A simulationbased dynamic stochastic route choice model for evacuation," Mathematical Problems in Engineering, vol. 2012, Article ID 396248, 18 pages, 2012.

[21] A. J. Pel, M. C. J. Bliemer, and S. P. Hoogendoorn, "A review on travel behaviour modelling in dynamic traffic simulation models for evacuations," Transportation, vol. 39, no. 1, pp. 97123, 2012.

[22] W. Yang, Key Techniques of Dynamic Traffic Induce Evacuation for Large-Scale Activities, Jilin University, 2011.

[23] H. Zhang, Research on Traffic Demand Forecasting and Evacuation Planning for Big Events, Wuhan University of Technology, 2007. 


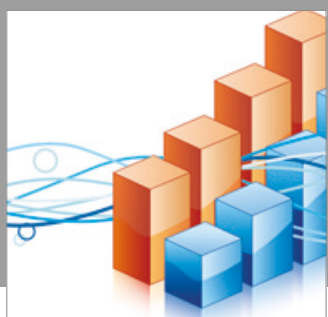

Advances in

Operations Research

vatersals

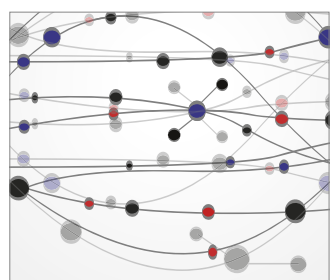

\section{The Scientific} World Journal
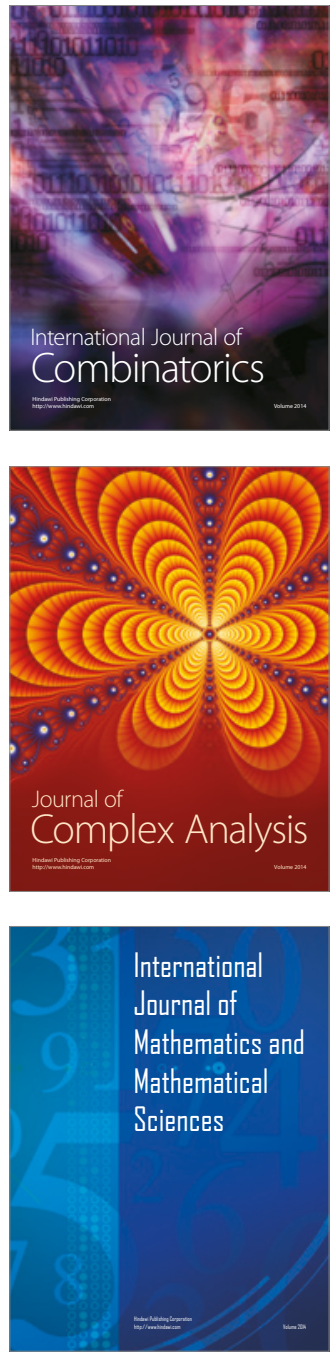
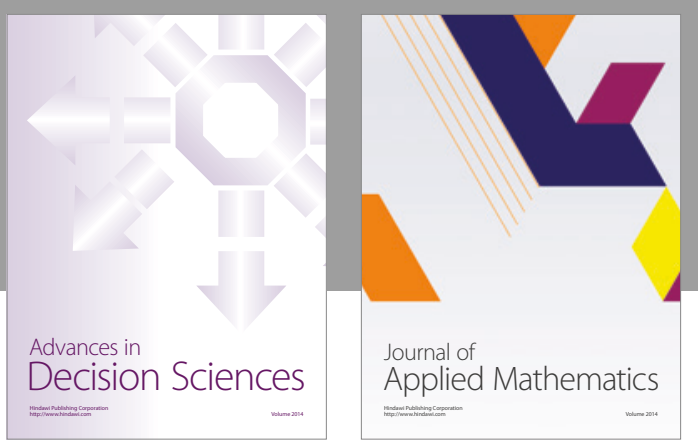

Algebra

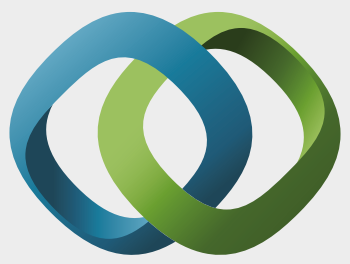

\section{Hindawi}

Submit your manuscripts at

https://www.hindawi.com
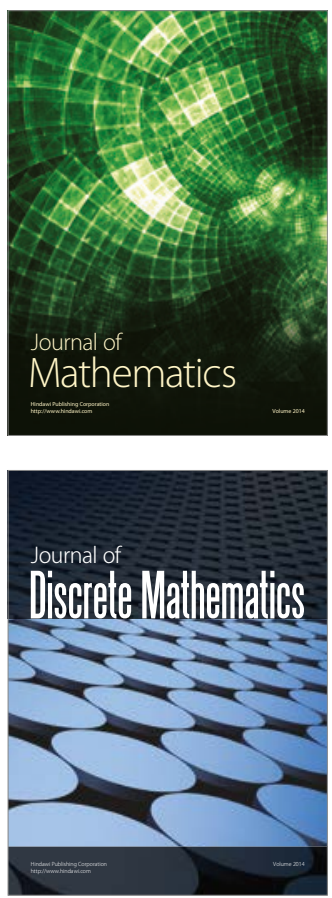

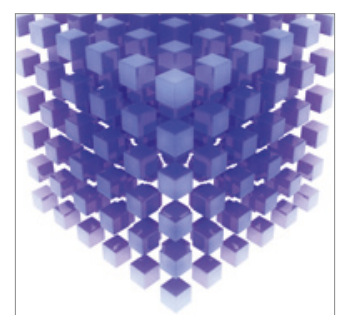

Mathematical Problems in Engineering
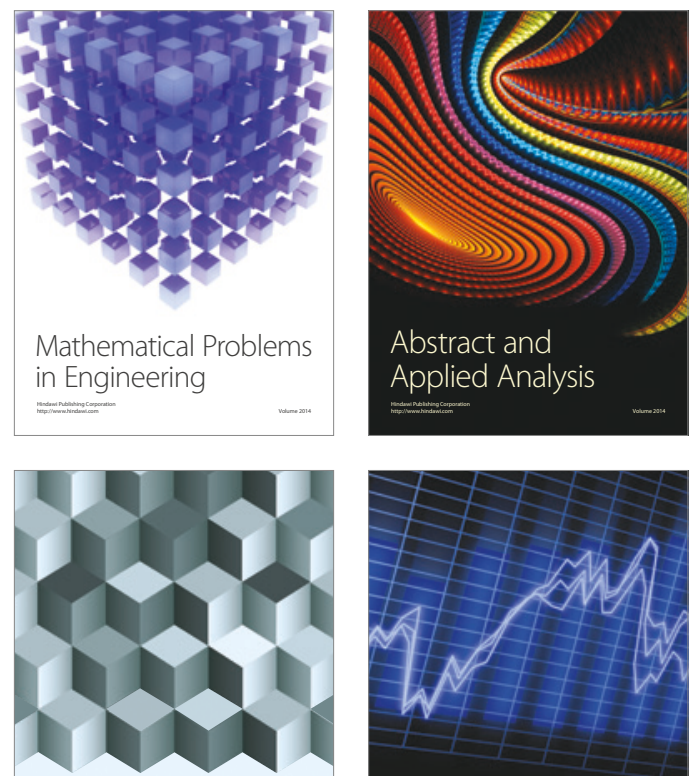

Journal of

Function Spaces

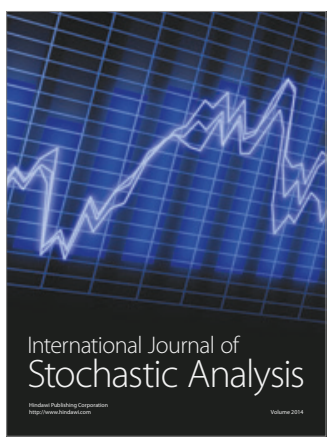

Probability and Statistics
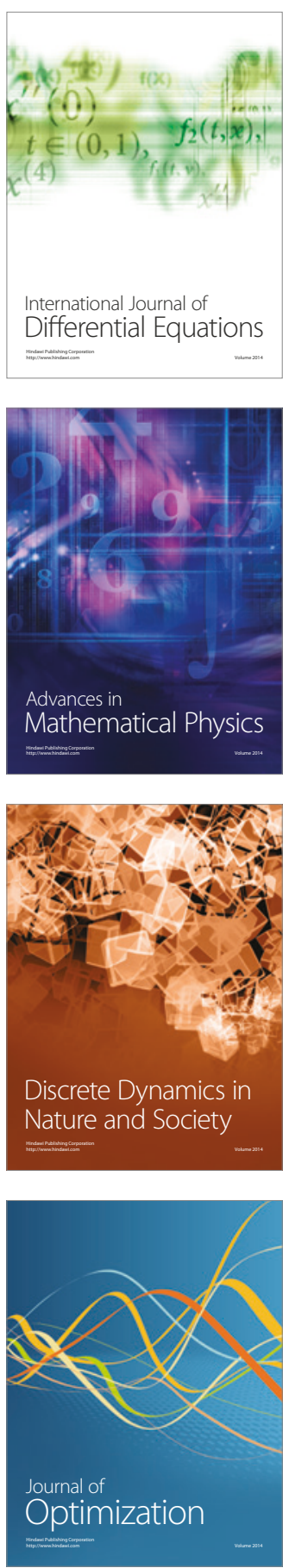